\title{
Globalising Economic Spaces, Uneven Development and Regional Challenges: Introduction to the Special Issue
}

\author{
Montserrat Pallares-Barbera, Pere Suau-Sanchez, Richard Le Heron, Martina \\ Fromhold-Eisebith
}

\begin{abstract}
Montserrat Pallares-Barbera, Department of Geography, Universitat Autònoma de Barcelona, Spain (montserrat.pallares@uab.cat)

Pere Suau-Sanchez, Department of Air Transport, Cranfield University, UK (p.suausanchez@cranfield.ac.uk)

Richard Le Heron, School of Environment, The University of Auckland, New Zealand (r.leheron@auckland.ac.nz)

Martina Fromhold-Eisebith, Institute of Geography, RWTH Aachen University, Germany

(m.fromhold-eisebith@geo.rwth-aachen.de)
\end{abstract}

\section{Introduction}

The phenomenon of spatially uneven development has always captured the interest of economic geographers, forming one of the foundation stones of the discipline and a major research focus in analyses of both advanced or emerging economies (Hayter and Patchell, 2011; Sheppard et al., 2009). The economic exploitation of localized resources to improve the quality of people's lives inevitably leads to widening of interregional economic disparities, engendering dynamics, which, over time, change little and are rarely reversed. Interregional disparities simply transform, assume different guises and, at times, shift between places. They never really vanish. And convergence is rare, as investigations of interregional disparities in Europe have shown (Badingera et al., 2004; Martin, 2001) and the USA (Caselli and Coleman, 2001). However, measuring the dynamics of interregional divergence and convergence is both demanding and problematic (Puga, 1999; Rey and Janikas, 2005). Consequently, the dynamics of spatially uneven development remain a major research question with significant and enduring policy relevance.

Against this backdrop, the papers in this volume make two contributions to the on-going debate on spatially uneven development. First, they demonstrate the broad range of approaches and perspectives used by economic geographers to explore this issue. And second, they highlight the economic processes and political concerns that are fundamental to its operation and amelioration - issues such as intensifying economic globalization, entrepreneurship processes, and corporate behaviour.

\section{Positioning this special issue in the economic geography literature.}

Building of previous research and especially the series of publications produced by the IGU Commission on the Dynamics of Economic Spaces, two key themes have come to prominence in economic geography research that relate strongly to spatially uneven economic development and the regional economic challenges it creates: 
- the nature and dynamics of relationships within and between networks, firms, and markets; and

- the need for a more "global" economic geography.

The first theme acknowledges the importance certain economic entities in shaping spatial patterns of development. These entities can be individual companies with their expansive organizational features (Phelps and Fuller, 2000), sets or networks of interacting firms (Cooke and Morgan, 1993; Yeung, 2000), or certain process fields or elements of value chains, such as customers and markets (Mitchell, 2007). Several contributions to this issue focus on this theme and show in detail how firms, networks and market demand have in specific cases shaped, framed and controlled the dynamics of interregional economic disparities and regional economic challenges, and how agencies have acted to solve the regional challenges that have been created.

The second theme, which calls for a broadening of views on international development interdependencies, expresses the need for a more "global" economic geography. Not only issues of globalized production and their regionally varying impacts need to be on this agenda (Coe et al., 2008), but also neglected world regions and actor groups, and a wider view of the interdependencies of economic, social and political process in a local-global perspective need to be included (Dicken, 2011).

Since the beginning of the present century, as economic perspectives have changed, attempts have been made to reconceptualise the spatial unevenness that has resulted. Economic geography concepts and language have been extended to include relational issues including networks, value chains and flexibility, with more emphasis being placed on small firm dynamics and services. As ICT has expanded and elaborated, the importance of global-local relationships has been thrown into prominence (Storper, 1997), together with issues of competition, cooperation, collaboration, networking and territoriality (Päivi Oinas and Bjørn Asheim, 2002). Additionally, notions of diversity, innovativeness, maturity and multiple scales have been incorporated into the debates on the significance of proximity for economic performance (Lagendijk and Oinas, 2004). At the same time, trying to understand the 'new economic spaces' and 'new economic geographies' that have been created has become a major research task (Le Heron and Harrington, 2004). When linked to the growing significance of politics, the creation of these new economic landscapes is generating a new "ethical economic geography" (Gatrell and Reid, 2006).

Against the background of changing theoretical understandings in economic geography and the rise of relational and evolutionary economic thinking, important questions remain concerning our understanding of how regional economies survive, grow, fail or decline as national and international economic circumstances change. For the research presented in this collection studies, three questions and areas of discussion and debate are especially noteworthy:

- how can regions sustain or gain economic strength within regional hierarchies;

- how do the environmental challenges that are now gaining prominence and public recognition impact of regional economic dynamics; and

- how do issues of symbolic value, created identities and constructivist forces impact on the spatial dynamics of economic regions?

The first area of debate refers to the specific challenges posed to regions situated along the loser/winner continuum of uneven development. All leading regions try to stay ahead and not fall behind, at least by means of public discourse (Bristow, 2005). In a world where spatial patterns of unevenness tend to become more volatile virtually 
each year, substantial efforts are required for keeping hitherto winning regions in a superior position. Representing the other side of the coin, the lagging regions that occupy inferior positions in the landscape of economic unevenness, often set in the rural context of a peripheral location, struggle to gain in rank and to receive a growing share of the wealth created in the global economy (Dunford and Smith, 2000). This reshaping of unevenness raises questions about how certain economic activities and actor initiatives may help regions stay ahead or catch up in the dynamics of competitive positioning.

The second area of debate centres on the growing importance of environmental concerns and claims for ecologically sustainable, resource preserving regional development, positioned in a challenging framework of economic globalisation (Hayter, 2008). Climate change and the growing demand to reduce $\mathrm{CO}_{2}$ emissions are impacting strongly on the behaviour of firms, regions and nations, with important consequences for shifting spatial patterns of unevenness. Some of the papers in this issue provide examples of what can be done and how this affects the fabric of regional social and economic interaction.

The third area of debate, relates to the 'cultural turn' in economic geography (Barnes, 2001), and highlights the often decisive influence of subjective representations, ascribed symbolic values and manipulative discourse on regional development. It suggests that uneven development can often be less determined by the endowment of places with resources, people and infrastructure, but rather that it is socially and intentionally constructed by means of discourse (Gonzalez, 2011). This adds new dimensions to understanding the positioning of regions in a globalizing world, suggesting very different grounds for regional catching-up. Whether these processes can survive the Euro crisis and widening global recession remains open to debate.

\section{The focus of the issue}

Against this backdrop of shifting perspectives in economic geography, the aims of this issue are two-fold. First, it seeks to spin further the colourful threads of thinking within economic geography to deepen our understanding of uneven economic development and associated regional challenges. It seeks to build on and add to the rich tradition of work in the aspect of geography as it seeks to understand the impact increasing globalization. Second, it attempts to highlight new trends and tendencies together with emergent constellations of processes and fields of power that mark the evolution of interregional disparities in an era of globalisation. As such it seeks to show how and where new institutional and political interventions might be needs and at what scales they might need to be applied.

The central focus and argument developed throughout this issue can thus be summarised as elucidating the simple but powerful idea of 'actors making a global stage'. This puts into terms both the crucial role of individual entities in shaping uneven development and the proliferating spatial implications of their actions, which, in turn, set the stage and conditions for the behaviour of economic entities. The entire process field created by virtue of this mutual interaction produces and often reinforces unevenness. In this situation institutional mediation and responses are needed, first on a range of scales - but especially the regional level -, and second, for the provision of institutional conditions that encourage alternatives to flourish.

In order to capture the overarching objectives and focus of this issue, the following leading questions can be posed: 
- How do patterns of regional uneven development now show themselves and how do they differ from patterns in the past? Have any changes improved or worsened local economic prospects?

- How do the separate elements of economic activity - such as companies, networks, value chains and markets for example - shape uneven and unequal spatial development demand? What policy changes and policy reactions have they created?

- How is globalising economic spaces influencing or being influence by these shifting forces of economic agency? How does this differ between regions and localities?

- What institutional and policy approaches offer options to create better chances for regions and actor groups in a globalized environment?

In the following section we will keep these essential questions in mind when presenting an overview of the contents and contributions assembled in this issue.

\section{Organisation of the issue}

The papers in this issue have been organized in sections to reflect on the four sets of questions posed in the preceding section that are central to the development of a deeper understanding of globalising economic spaces, uneven economic development and regional challenges. The papers have been grouped into four parts:

- Geographic dynamics in uneven development;

- Making and taking value in value chains;

- Initiatives and interventions: enterprise and economy';

- Initiatives and interventions: the environmental perspective.

The first set of papers on the geographic dynamics in uneven development explore continuing issues and concerns and review and revisit some basic ideas and actual expressions of uneven development and unequal exchange. This part emphasises why economic geographers must continue to address these issues, and how geographies of unevenness have factually evolved in recent years, looking at examples in Latin America and China. The cases presented reveal the multiplicity of factors, actors and dimensions that shape unequal development patterns especially in newly emerging economies, which are usually considered as winners of global economic shifts. But not every place can profit from this level of inclusion.

The first contribution by Colin M. Kennedy and Warwick E. Murray titled 'Growing apart? The persistence of inequality in Chile, 1964-2010' addresses the phenomenon of interregional disparities from a wide angle and illustrates how different policy regimes and various types of intervention reduce inequality have not succeeded in breaking the persistent patterns of significant unevenness in Chile. While overall improvements of living conditions and economic indicators have been achieved in the course of the country's integration into the global economy, this just very slowly translates into a more uniform and even participation of regions or social groups in the country's growing wealth.

The paper by Rocío Rosales Ortega on 'Urban-rural relations in the Central Region of Mexico: A Viewpoint from Tlaxcala' takes a more positive view of local economic development by highlighting the influences of another process field - rural industrialisation - and consequently, the sectoral diversification of economic activities outside of urban core areas, and changes in wider regional dynamics. Based on empirical research, the author provides an instructive account on how internationally 
embedded production activities have transformed the division of functions and mutual dependencies between urban and rural areas in parts of Mexico. The analysis supports general assumptions on ideas like 'rurality' and 'rurbanization' that promise opportunities for this type of region to catch-up economically.

Shifting the focus to China, Liu Xuan and $\mathrm{Li}$ Xin discuss 'The land administration system, structured land rent residuals and China's urban sprawl - a case study of Dashi, Guangzhou'. Here the urban-rural development continuum is revisited by pointing out the role played by changes in land ownership rights for urban sprawl. The Chinese Land Administration System is introduced as offering options for adjusting spatial patterns of development to market demand by virtue of 'land rent residuals', a mechanism that induces leapfrogging expansion of urban style development projects in the urban periphery. This helps to reduce inequalities in some respects, yet creates problems of control and wealth distribution in others.

The last paper in this first part of the issue, on 'The location dynamics of firms in transitional Shanghai, 1978-2005' by Bo Qin and Sun Sheng Han, raises the interesting question of how the move of the Chinese economy towards market orientation has changed the previously state dominated location behavior and patterns of industrial firms in one of the most prosperous economic regions of the country. The authors search for major newly effective location factors through model calculations and reveal the major influence of distance and infrastructure on the process. Inequalities between central and peripheral urban locations have been reduced mainly by manufacturing and producer service firms as major actors.

While some papers in the first part of this issue already indicate the significant influence of companies' behaviour on shifts in intra- or inter-regional patterns of inequality, those of the second set of papers dig deeper into the heart of the issue, highlighting the 'making and taking value in value chains'. The papers contribute to the issue's general theme both theoretically and empirically. By unveiling vital links between increasingly globally oriented corporate behaviour and shifting regional impacts, the contributors break new ground and provide new insights into shifting patterns of economic unevenness.

Robert N. Gwynne starts this approach by analysing the 'Strategic evolution of Chilean wine firms: vertical integration and upgrading in Chile's Colchagua Valley'. Owing to a functional as well as a regional expansion of activities, Chile's winemakers have been able to substantially reduce the gap between their own quality and world market quality. This has resulted a surge in wine exports and corporate upgrading related to new products and processes, as well as organizational and marketing developments. The author shows how this has helped firms to gain a more powerful position in global commodity chains of the sector. A self-reinforcing process of inclusion has been set into motion, which also leaves its traces in a changing geography of wine production in Chile.

Addressing the same sector, but at a different location, David Hayward and Nicolas Lewis examine 'The construction and realisation of geographic brand rent in New Zealand wine'. Some cultural and identity related qualities, that have marginally been touched upon in the previous paper, are explored more fully. The fact that the global market value of a commodity, be it wine or other sensitive products, can strongly depend on its origin from a certain, labelled place, sheds new light on why interregional inequalities often persist. This paper reconfirms, however, that a growing integration into global value chains also bears some potential for geographic shifts in production within the country, favouring some rising locations over others. 
The contribution on 'Food Regimes Revisited: A New Zealand Perspective' by Michael Roche broadens the horizon and positions a case study on the meat industry into wider considerations on how constellations of value chain relations and company involvement have essentially changed in the recent phase of export oriented food production. Drawing on the concept of Food Regimes, and the Third Regime in particular, the author scrutinizes the validity of different, often divergent assumptions on the nature and characteristics of this regime for the chosen example. Some shifts in market access, corporate features and technology use can be noted, whose geographical implications remain to be further explored.

At the end of this second set of papers, Susan Fairgray, Christine Tamásy and Richard Le Heron pull together major aspects of the topic by addressing 'New geographies of accumulation, globalising firm networks and the role of the Auckland region in the Australasian economy'. They use concepts of global production chains and capital circuits, on the one hand, and logically connect these with the assessment of local-global development interdependencies of regions, on the other one. The comprehensive analysis of data sets on international companies located in Auckland reveals how international patterns of involvement expand and transform in a liberalizing regime and impact on the location itself.

The third and fourth sets of papers in this issue focus on initiatives and interventions'. They open up discussion on how adequately the continuing patterns and ongoing dynamics may or may not be sufficiently understood, how this has fuelled particular kinds of thinking about the dynamics of unevenness, and how this in turn has been institutionalized in particular sorts of regional policy. The first of these sets of papers explores enterprise and entrepreneurship, which can emerge from private as well as public initiative, as increasingly powerful engines for shaping the fate and spatial order of regions. The second set examines the growing importance of environmental perspectives.

In his paper on 'Global Businesses 'from Below': Ethnic Entrepreneurs in Metropolitan Areas" Pau Serra attempts to explain immigrant urban landscapes in more advanced economies. It is suggested that to appreciate these landscapes it is important to understand how a diversity of cultures have adjusted to a palimpsest of urban economic spaces. The results show a dynamic and global pattern of small economies fighting for survival in a wider space.

Rural spaces in more advanced economies are problem areas for economic geography research. They are in-between spaces where urban and rural concepts intersect and give fuzzy results. In their study on "Side activities of non-farmers in rural areas in the Netherlands", Marianna Markantoni and Dirk Strijker focus on marginal and complementary economic processes to enhance regional development. Rural spaces are transformed into places of consumption, which contain a diversification of service activities for urban-temporal demand. These new activities are conceptualized as side activities performed by farmers and non-farmers and that significantly affect local communities.

Sustainability and mobility are basic elements in the unevenness paradigm across regions. In his piece of work, "Impetus And Resistance To Changing WorkRelated Mobility Patterns in Catalonia: The Role of the Social Actors and Participation" Àngel Cebollada discusses how to find the right balance involving private and public agents in order generate sustainable social change.

In the next two papers, the empirical focus is shifted to China. First, Yimei Yin and Zhigao Liu revisit a well-trodden path in economic geography, the study of old industrial regions. In their paper on "Creating new path for Old Industrial Areas: A Case 
Study on Dalian city, China" the turmoil of economic reforms in the late 1970s, the most significant ones since Chinese Communist Party came into power, have raised economic, social and environmental issues which have to be addressed. Dalian city appears to be a successful exception in the transition towards the new deal of serviceoriented economy.

Reflecting developed country work on inequalities within city-regions, Guo Chen's work on "State Rescaling, Contested Space, and Inequality in the Globalizing City-regions of China: Conceptual Issues and Empirical Evidence" discusses the different mosaic-like socio-spatial landscape of three important city-regions in China: Shanghai, Guangzhou, and Beijing. Although all three city-regions are on the same hierarchical level, each uses a different combination of strategies. Basically, these landscapes have resulted from two combined forces playing at different levels; a 'downward' force of decentralization of responsibility for economic development, and an 'upward' force centralizing power to larger urban cores.

The final set of papers, explores "The environmental perspective" of economic activity; with the actions of social and economic agents producing 'unwanted' and nonmarketable environmental impacts in places. Negative externalities involve agents at different levels; some are responsible for producing them and others endure their consequences. Uneven sustainability depends of local development strategies. This topic is discussed by Marta Pallares-Blanch in "Natural Protected Areas and Rural/Local Development: A Sustainable Strategy in Remote Areas". It presents the dilemma of adopting conservation environmental principles and coping with underdevelopment, against launching pro-active rural economic development policies which could have negative environmental side effects for protected areas. She goes on to advocate designing rural policies, based on urban-rural dynamics, which would enhance natural protected areas and their hinterland.

In the most advanced economies, companies in the architecture, contracting, and engineering industries offer their prospective clients the option to build green. In her paper, "Building quality, building green: conventions theory and industry transformation", Julie Cidell explores important elements of the emerging ethical stance in the construction industry.

Environmental services broadly consist of consulting and remediation, on the one hand, and wastewater treatment and solid waste management, on the other. In his paper, "Geographical Dynamics of Environmental Service Firms at Metropolitan and National Scales in the United States: The Case of Pittsburgh, Pennsylvania", James T. Hathaway examines how environmental services have evolved in one of the older industrial metropolitan areas in the United States, and how, driven by Technology Council policies, environmental services have partially replaced the reducing steel industry

\section{Concluding Comments}

Spatial uneven development in a globalized world is an important phenomenon driven by its fast dynamics and its manifestation across a wide range of economic agents and its regional challenges. The papers in this issue offer a wide-ranging, geographically diverse and challenging contribution to the important on-going debate on differential economic growth that involves a number of academic disciplines. Individually, they raise important research issues, and collectively they suggest the need for significant theoretical rethinking of our understanding of regional economic sustainability and vitality. The challenge is to link these ideas and new areas of thinking into the realities of an increasingly connected world. 


\section{Acknowledgements}

We are very grateful to the international reviewers who refereed individual papers. The refereeing process consisted of two parts: an assessment by a referee selected from the conference participants and an international referee. The reviewing process was anonymous.

\section{References}

Badingera, H., Müller, W. and Tondla, G. (2004) 'Regional Convergence in the European Union, 1985- 1999: A Spatial Dynamic Panel Analysis’. Regional Studies, 38, 241-253.

Barnes, T.J. (2001) 'Retheorizing Economic Geography: From the Quantitative Revolution to the "Cultural Turn". Annals of the Association of American Geographers, 91, 546-565.

Bristow, G. (2005) 'Everyone's a 'winner': problematising the discourse of regional competitiveness'. Journal of Economic Geography, 5, 285-304.

Caselli, F. and Coleman, W.J. (2001) 'The US structural transformation and regional convergence: A reinterpretation'. Journal of Political Economy, 109, 584-616.

Coe, N.M., Dicken, P. and Hess, M. (2008) 'Introduction: global production networks debates and challenges'. Journal of Economic Geography, 8, 267-269.

Cooke, P. and Morgan K. (1993) 'The network paradigm: new departures in corporate and regional development'. Environment and Planning D: Society and Space, $11,543-564$.

Dicken, P. (2011) Global Shift. Mapping the Changing Contours of the World Economy. $6^{\text {th }}$ edition, New York: Guilford Press.

Dunford, M. and Smith, A. (2000) 'Catching Up or Falling Behind? Economic Performance and Regional Trajectories in the "New Europe". Economic Geography, 76, 169-195.

Gatrell, J.D., Reid, N. (2006) Enterprising Worlds. A Geographic Perspective on Economics, Environments and Ethics. Dordrecht: Springer.

Gonzalez, S. (2011) 'The North/South divide in Italy and England: Discursive construction of regional inequality'. European Urban and Regional Studies, 18, $62-76$.

Hayter, R. (2008) 'Environmental Economic Geography’. Geography Compass, 2, 831850.

Hayter, R. and Patchell, J. (2011) Economic Geography. An Institutional Approach. Don Mills, ON: Oxford Univ. Press.

Lagendijk, A. and Oinas, P. (eds). (2004). Proximity, Distance and Diversity: Issues on Economic Interaction and Local Development. Aldershot: Ashgate.

Le Heron, R. and Harrington, J. W. (2004). New Economic Spaces: New Economic Geographies. Aldershot: Ashgate.

Martin, R. (2001) 'EMU versus the regions? Regional convergence and divergence in Euroland'. Journal of Economic Geography, 1, 51-80.

Mitchell, T. (2007) The properties of markets, in D. MacKenzie, F. Muniesaand and L. Siu (eds) Do economists make markets? Princeton, N.J.: Princeton Univ. Press, 244-275.

Oinas, P. (2002). Competition and collaboration in interconnected places: Towards a research agenda. Geografiska Annaler: Series B, Human Geography, August 2002. Volume 84, Issue 2, pp. 65-76. 
Participants in the Economic Geography 2010 Workshop (2011) 'Editorial: Emerging Themes in Economic Geography. Outcomes of the Economic Geography 2010 Workshop'. Economic Geography, 87, 111-126.

Phelps, N.A. and Fuller, C. (2000) 'Multinationals, Intracorporate Competition, and Regional Development'. Economic Geography, 76, 224-243.

Puga, D. (1999) 'The rise and fall of regional inequalities'. European Economic Review, 43, 303-334.

Rey, S.J. and Janikas, M.V. (2005): 'Regional convergence, inequality, and space'. Journal of Economic Geography, 5, 155-176.

Sheppard, E., Porter, P.W., Faust, D.R. and Nagar, R. (2009) A World of Difference. Encountering and Contesting Development. $2^{\text {nd }}$ edition. New York: Guilford Press.

Storper, M. (1997). The regional world: territorial development in a global economy. New York: Guilford Press.

Yeung, H.W. (2000) 'Organizing 'the firm' in industrial geography I: networks, institutions and regional development'. Progress in Human Geography, 24, 301315. 